\title{
MATHEMATICAL MODELING OF EXPERIMENT ON BERKOVICH NANOINDENTATION OF ZRN COATING ON STEEL SUBSTRATE
}

\author{
Evgeniy Sadyrin*, Andrey Vasiliev, Sergei Volkov \\ Don State Technical University, Research and Educational Center "Materials ", 1 Gagarin Square, \\ Rostov-on-Don, 344000, Russia \\ * corresponding author: ghostwoode@gmail.com
}

\begin{abstract}
In the present paper the experiment on Berkovich nanoindentation of $\mathrm{ZrN}$ coating on steel substrate is modelled using the proposed effective mathematical model. The model is intended for describing the experiments on indentation of samples with coatings (layered or functionally graded). The model is based on approximated analytical solution of the contact problem on indentation of an elastic half-space with a coating by a punch. It is shown that the results of the model and the experiment are in good agreement.
\end{abstract}

KEYwords: Coating, contact mechanics, layered composite, mathematical modeling, nanoindentation, scanning electron microscopy.

\section{INTRODUCTION}

Nanoindentation is a widespread technique aimed at researching of the physical and mechanical properties of materials [1]. During experiment the dependence of the penetration depth of the special probe - indenter - into the sample on the applied load is acquired (loaddisplacement curve). For different purposes indenters with different tip shapes are required. A pyramid with a triangular cross-section and a spherical blunting of the tip (Berkovich indenter) is one of the most popular shapes. Since it is difficult to avoid plastic deformation in such an experiment even with a small load, Oliver and Pharr proposed to analyze the unloading part of the load-displacement curve to determine the elastic properties of the sample [2]. They described the method for evaluation of the Young's modulus of the sample based on the analysis of the indentation stiffness - the derivative of the force with respect to the indentation depth - at the maximum indentation depth. In such a case, the contact area must be determined. For homogeneous materials, contact area can be found from calibration experiments on samples with previously studied properties [3]. However, it was shown [4, 5] that the presence of an inhomogeneous or layered coating on the material significantly influences the size of the contact area. One can determine elastic moduli of an isotropic elastic material by establishing the real indentation contact area [6] but it is nearly impossible for submicron indentation depth.

In the present study, an effective mathematical model, taking into account the layered or continuously inhomogeneous structure of the sample, is proposed for the description of nanoindentation experiment of the $\mathrm{ZrN}$ coating on the steel substrate. $\mathrm{ZrN}$ coatings are used in practice to improve the ability of various tools for drilling and milling aluminum and titanium alloys
[7. 8], for increasing hardness and abrasive resistance of surgical tools [9], decorative purposes [10] etc. The results of the mathematical modeling are compared to the results of nanoindentation experiment.

\section{MATERIALS}

Prior to coating deposition, the preparation of steel 3Cr3Mo3V (analogue to H10 [11) substrate was carried out by a standard metallographical method using linear precision saw Isomet 4000 (Buehler, USA) and grinding-polishing machine Metaserv 250 (Buehler, PRC). The substrate was mirror polished in several steps with the abrasive particles of various diameters (down to $0.05 \mu \mathrm{m}$ ). The $\mathrm{ZrN}$ coating was deposited on the ion-plasma sputtering unit Bulat 6 . The substrate was heated to $550-600{ }^{\circ} \mathrm{C}$, ionic surface cleaning was conducted, then deposition was carried out at $60-65 \mathrm{~V}$ supply voltage of the substrate and 130-140 A current.

The microgeometrical characteristics of the sample were studied for using Contour Elite 3D Optical Microscope (Bruker, Belgium). Figure 1 shows surface profiles constructed in the software Vision64 (Bruker, Belgium) in horizontal and vertical directions (filter type: Gaussian regression, long cutoff $250 \mu \mathrm{m}$ ). The values for the average roughness $\mathrm{R}_{a}$ and the maximum roughness height $\mathrm{R}_{t}$ were calculated according ISO 4287 12 standard and are summarized in the Table 1] These values were used for choosing optimal parameters for the nanoindentation experiment. The extremely high $\mathrm{R}_{t}$ values can be explained by the presence of the artefacts of deposition on the surface of the coating: caverns and crystallized droplets (Figure 2 a).

One of the crucial characteristics for the mathematical modelling, the coating thickness, was determined using ion beam etching on the scanning electron microscope (SEM). Its value reached $2.7 \mu \mathrm{m}$ after ap- 

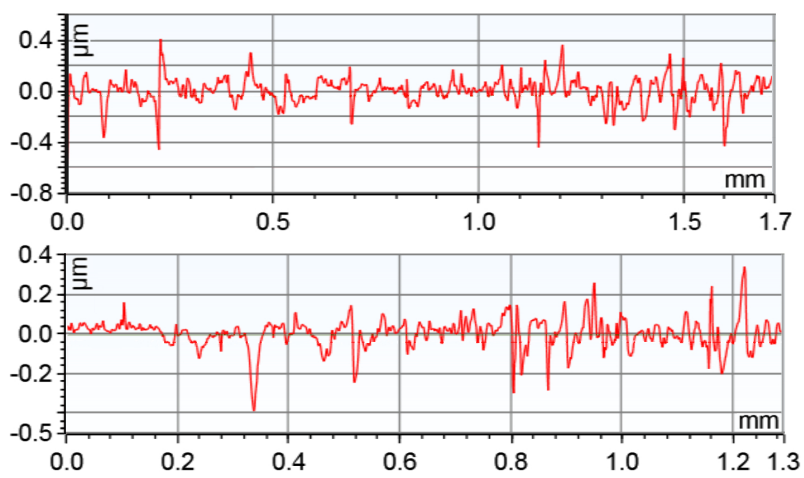

Figure 1. Surface profile of $\mathrm{ZrN}$ coating across directions: a) horizontal; b) vertical.

\begin{tabular}{ccc}
\hline Characteristic & $\begin{array}{c}\text { Horizontal } \\
\text { direction, } \\
{[\mathrm{m}]}\end{array}$ & $\begin{array}{c}\text { Vertical } \\
\text { direction, } \\
{[\mu \mathrm{m}]}\end{array}$ \\
\hline $\mathrm{R}_{a}$ & 0.073 & 0.052 \\
$\mathrm{R}_{t}$ & 0.984 & 0.73 \\
\hline
\end{tabular}

TABLE 1. ZrN coating microgeometrical characteristics.

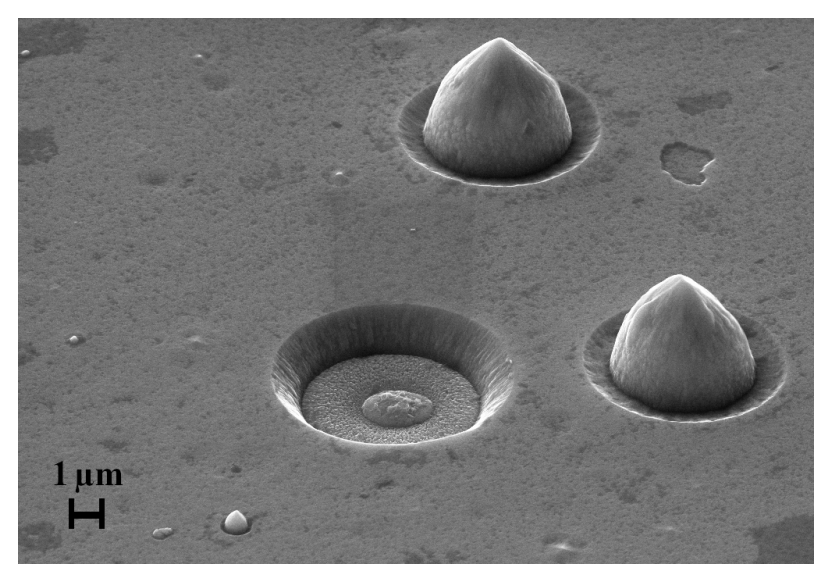

a)

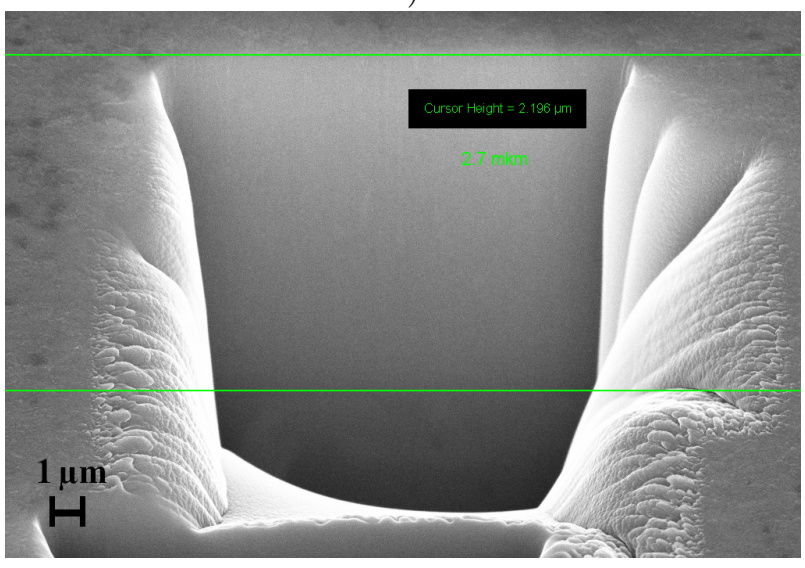

b)

Figure 2. ZrN coating research using SEM: a) artefacts of deposition; b) coating thickness.

propriate tilt correction in the software of the device (Figure 2p).

\section{Methods}

Nanoindentation research was conducted on the Nanotest 600 Platform 3 (Micro Materials, UK) device. All the experiments were made in the closed chamber at a constant temperature of $27.0 \pm 0.1{ }^{\circ} \mathrm{C}$, the Berkovich indenter with a diamond tip was used. The following load profile was applied: the load linearly increased for 30 seconds, held constant for 30 seconds, then linearly decreased for 30 seconds. Before the coating investigation the value for the Young's modulus E of the substrate was obtained for the needs of mathematical modelling, it reached $267.11 \pm 10.65 \mathrm{GPa}$.

The value of Poisson's ratio of the steel substrate was taken $\nu=0.3[13$. The series of nanoindentation experiments was conducted for different maximum loads $\mathrm{P}_{\max }$ : load varied within $5 \mathrm{mN} \leq \mathrm{Pmax} \leq 280$ $\mathrm{mN}$. The corresponding maximum indentation depth $\mathrm{h}_{\max }$ was as follows: $65 \mathrm{~nm} \leq \mathrm{h}_{\max } \leq 1414 \mathrm{~nm}$. For each $\mathrm{P}_{\max }, 8$ to 12 identical indentations were carried at different locations, the results were averaged.

\section{Results AND Discussion}

The experimentally collected characteristics allowed us to perform the mathematical modelling of the indentation process. The Berkovich indenter was modeled by an elastic body of conical shape with the elastic moduli $\mathrm{E}_{\text {punch }}=1131 \mathrm{GPa}$ and $\nu_{\text {punch }}=0.07$. The $\mathrm{ZrN}$ on the steel substrate system was modeled by a half-space with a coating since the contact area between indenter and the sample is much smaller than the sample size. The contact problem was reduced to the solution of the dual integral equation, the solution of which was constructed by the authors earlier [14. Using the bilateral asymptotic method, the approximated analytical expressions for the indentation stiffness, force and indentation depth were obtained $(1)-(3)$.

In the formulas above $a-$ the radius of the contact area $(\mathrm{m}) ; \alpha-$ the half of the angle of the conical punch opening; $\lambda=H / a-$ the dimensionless thickness of the coating; $H$ - the coating thickness $(\mathrm{m})$; $E_{e f}^{(s)}=E /\left(1-v^{2}\right)-$ the effective elastic modulus of the substrate $(\mathrm{Pa}) ; A_{i}, C_{i}, D_{i}-$ the constants depending on the elastic properties of the coating and the substrate 14. Expressions (1)-(3) are asymptotically exact for $\lambda \rightarrow 0$ and $\lambda \rightarrow \infty$. The functions $P_{0}(\lambda), \delta_{0}(\lambda)$ describe the influence of the coating on the characteristics of the contact. It is clear that if the coating thickness tends to zero $(\lambda \Rightarrow 0)$, then $P_{0}(\lambda) \rightarrow 1, \delta_{0}(\lambda) \rightarrow 1$, the formulas (1) coincide with the formulas for the homogeneous half-space without coating [15]. The conical punch opening angle was chosen similarly to [3] on the basis of the following considerations. Let $A_{c}^{\text {Beek }}$ - the contact area during the Berkovich indentation, obtained from the calibrations of the device: $A_{c}^{\text {Perk }}=23,33 \chi^{2}+3213,76 \chi$, and $A_{c}^{\text {con }}$ - the contact area during the conical punch indentation. From geometric considerations $A_{c}^{\text {con }}=$ 


$$
\begin{gathered}
S=2 a E_{\text {ef }}^{(s)} \frac{P_{0}(\lambda)}{\delta_{0}(\lambda)}, P=\frac{E_{\text {ef }}^{(s)} a \chi}{2} P_{0}(\lambda), \delta=\frac{\pi \chi}{2} \delta_{0}(\lambda), \chi=a \operatorname{ctg} \alpha \\
P_{0}(\lambda)=1+2 \lambda \sum_{i=1}^{N}\left(\frac{C_{i}}{A_{i}}\left[\operatorname{ch}\left(\frac{A_{i}}{\lambda}\right)-\frac{\lambda}{A_{i}} \operatorname{sh}\left(\frac{A_{i}}{\lambda}\right)\right]+\frac{D_{i}}{A_{i}}\left[\frac{\lambda}{A_{i}}-\frac{\lambda}{A_{i}} \operatorname{ch}\left(\frac{A_{i}}{\lambda}\right)+\operatorname{sh}\left(\frac{A_{i}}{\lambda}\right)\right]\right) \\
\delta_{0}(\lambda)=1+\sum_{i=1}^{N} \lambda A_{i}^{-1}\left(C_{i} \operatorname{ch}\left(A_{i} \lambda^{-1}\right)+D_{i} \operatorname{sh}\left(A_{i} \lambda^{-1}\right)\right)
\end{gathered}
$$

$\pi a^{2}=\pi \chi^{2} / \cot ^{2} \alpha$. Equating $A_{c}^{\text {Berk }}=A_{c}^{\text {con }}$, we obtained:

$$
\alpha=\frac{180}{\pi} \operatorname{arccot}\left(\frac{17,725 \sqrt{\chi}}{\sqrt{2333 \chi+321300}}\right)
$$

Figure 3 shows the graphs of the indentation stiffness as the function of the maximum indentation depth $\mathrm{h}_{\max }$. It is clearly seen, that the experiment and the theory agree well on the entire investigated range (even despite the steps associated with the destruction of the sample were observed on the loading curves at $\sim 500 \mathrm{~nm}$ and $\sim 800 \mathrm{~nm}$ indentation depths).

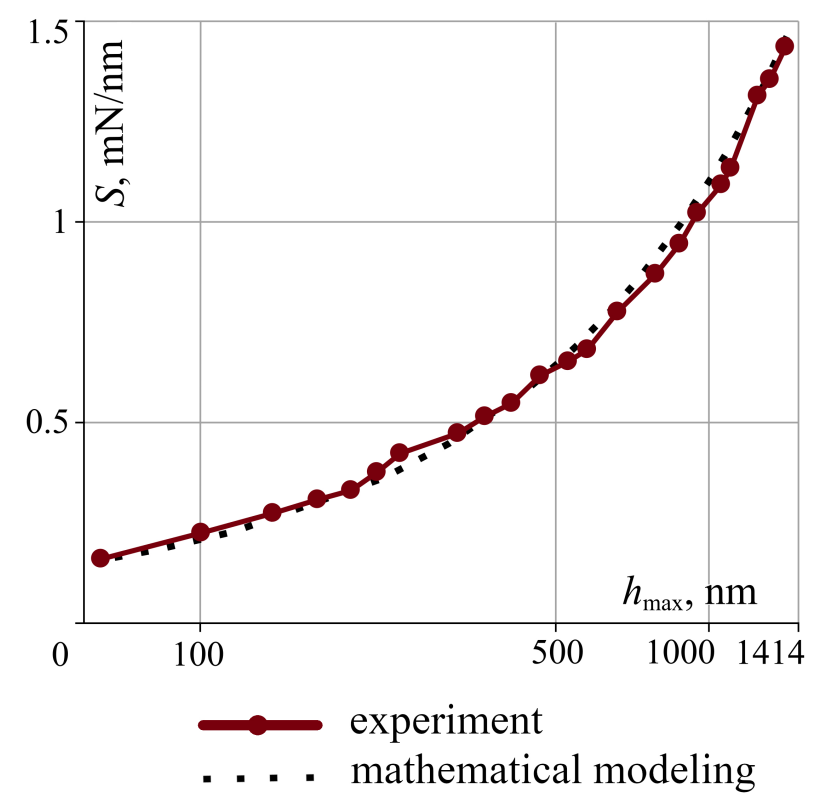

Figure 3. Dependence of the indentation stiffness $\mathrm{S}$ on the maximum indentation depth for the $\mathrm{ZrN}$ coating on the steel substrate according to mathematical modelling and nanoindentation tests

\section{Conclusions}

The paper presents the second step in testing of the mathematical modelling for describing the results of the nanoindentation experiments on $\mathrm{ZrN}$ coatings [16]. The results obtained show that the chosen mathematical model gives possibility to effectively describe the nanoindentation experiments with $\mathrm{ZrN}$ coatings deposited on steel substrates. As a consequence, the proposed mathematical model may be used to reconstruct Young's modulus of such coatings for improving the technology of $\mathrm{ZrN}$ coating deposition. In this regard, the further research concerning simplification of the model proposed (so the kernel transform to be approximated by a ratio of two quadratic functions containing only one parameter) for the engineering applications [17] is of significant interest.

\section{ACKNOWLEDGEMENTS}

This work was supported by the Russian Science Foundation (RSF) through grant No. 19-19-00444. E.V. Sadyrin was supported by the scholarship of the President of the Russian Federation no. SP-3672.2018.1. Experiments on nanoindentation were made in Nanocenter of Research and Education Center "Materials", Don State Technical University (http://nano.donstu.ru).

\section{REFERENCES}

[1] A. C. Fischer-Cripps. Nanoindentation testing. In Nanoindentation, pp. 20-35. Springer New York, 2002. DOI:10.1007/978-0-387-22462-6_2.

[2] W. Oliver, G. Pharr. An improved technique for determining hardness and elastic modulus using load and displacement sensing indentation experiments. Journal of Materials Research 7(6):1564-1583, 1992. DOI:10.1557/jmr.1992.1564.

[3] Y. I. Golovin. Nanoindentation and its capabilities. Mashinostroyeniye 2009.

[4] A. Vasiliev, S. Volkov, A. Belov, et al. Indentation of a hard transversely isotropic functionally graded coating by a conical indenter. International Journal of Engineering Science 112:63-75, 2017. DOI:10.1016/j.ijengsci.2016.12.002.

[5] E. V. Sadyrin, B. I. Mitrin, L. I. Krenev, et al. Evaluation of mechanical properties of the two-layer coating using nanoindentation and mathematical modeling. In Springer Proceedings in Physics, pp. 495-502. Springer International Publishing, 2018. DOI:10.1007/978-3-319-78919-4_39.

[6] V. B. Zelentsov, E. V. Sadyrin, A. G. Sukiyazov, N. Y. Shubchinskaya. On a method for determination of poisson's ratio and young modulus of a material. MATEC Web of Conferences 226:03027, 2018. DOI:10.1051/matecconf/201822603027.

[7] J. Vetter. Vacuum arc coatings for tools: potential and application. Surface and Coatings Technology 7677:719-724, 1995. DOI:10.1016/0257-8972(95)02499-9. 
[8] H. Randhawa, P. Johnson. Technical note: A review of cathodic arc plasma deposition processes and their applications. Surface and Coatings Technology 31(4):303-318, 1987. DOI:10.1016/0257-8972(87)90157-5

[9] J. Kadlec, Z. Joska, J. Kadlec. Study of biocompatible $\mathrm{ZrN}$ and $\mathrm{ZrN} / \mathrm{DLC}$ coating deposited on medical tools. ECS Transactions 48(1):315-318, 2014. DOI:10.1149/04801.0315ecst

[10] M. Nose, M. Zhou, E. Honbo, et al. Colorimetric properties of $\mathrm{ZrN}$ and TiN coatings prepared by DC reactive sputtering. Surface and Coatings Technology 142-144:211-217, 2001. DOI:10.1016/s0257-8972(01)01196-3.

[11] T. Okuno. Effect of microstructure on the toughness of hot work tool steels, AISI h13, h10, and h19. Transactions of the Iron and Steel Institute of Japan 27(1):51-59, 1987. DOI:10.2355/isijinternational1966.27.51

[12] Geometrical Product Specifications (GPS) - Surface texture: Profile method - Terms, definitions and surface texture parameters. Standard, International Organization for Standardization, Geneva, CH, 1997.

[13] V. Bhandari. Machine design data book. McGraw-Hill Education, 2014.
[14] S. Aizikovich, A. Vasil'ev, S. Volkov. The axisymmetric contact problem of the indentation of a conical punch into a half-space with a coating inhomogeneous in depth. Journal of Applied Mathematics and Mechanics 79(5):500-505, 2015. DOI:10.1016/j.jappmathmech.2016.03.011

[15] I. N. Sneddon. Fourier transforms mcgraw-hill. New York pp. 445-49, 1951.

[16] A. S. Vasiliev, E. V. Sadyrin, B. I. Mitrin, et al. Nanoindentation of $\mathrm{ZrN}$ coatings on silicon and copper substrates. Russian Engineering Research 38(9):735-737, 2018. DOI:10.3103/s1068798x18090289.

[17] E. V. Sadyrin, A. S. Vasiliev, S. S. Volkov, et al. Simplified analytical solution of the contact problem on indentation of a coated half-space by a spherical punch. In Boundary elements and other mesh reduction methods xli. wit press, 2018. DOI:10.2495/be410191 